\title{
Ablative dose stereotactic body radiation therapy for oligometastatic disease: a prospective single institution study
}

\author{
P. BURKON ${ }^{1,2}$, T. KAZDA ${ }^{1,2,3}$, P. POSPISIL ${ }^{1,2}$, M. SLAVIK ${ }^{1,2, *}$, L. KOMINEK ${ }^{1}$, I. SELINGEROVA ${ }^{4,5}$, D. M. BLAKAJ ${ }^{6}$, T. PROCHAZKA $^{1}$, M. VRZAL $^{1}$, \\ Z. REHAK ${ }^{4,7}$, P. SLAMPA ${ }^{1,2,4}$
}

${ }^{1}$ Department of Radiation Oncology, Masaryk Memorial Cancer Institute, Brno, Czech Republic; ${ }^{2}$ Department of Radiation Oncology, Faculty of Medicine, Masaryk University, Brno, Czech Republic; ${ }^{3}$ Central European Institute of Technology, Masaryk University, Brno, Czech Republic; ${ }^{4}$ Regional Center for Applied Molecular Oncology (RECAMO), Masaryk Memorial Cancer Institute, Brno, Czech Republic; ${ }^{5}$ Department of Mathematics and Statistics, Faculty of Science, Masaryk University, Brno, Czech Republic; ${ }^{6}$ Radiation Oncology Department, Arthur James Cancer Center, The Ohio State University, Columbus, USA; ${ }^{7}$ Department of Nuclear Medicine and PET Center, Masaryk Memorial Cancer Institute, Brno, Czech Republic

${ }^{*}$ Correspondence: slavik@mou.cz

Received July 31, 2018 / Accepted October 17, 2018

\begin{abstract}
Localized, metastasis-directed stereotactic body radiation therapy (SBRT) of oligometastatic disease (OD) is currently rapidly evolving standard of care in many institutions. Further reports of outcomes are required to strengthen the level of evidence in the absence of comparative trials evaluating different practical procedures. The aim of this prospective single institutional study is to analyse, in unselected cohort of patients from real-world clinical practice, the long-term survival, tumor control outcomes and safety of SBRT in OD (radical ablative radiotherapy with biological equivalent dose $\mathrm{BED}_{10}>100 \mathrm{~Gy}$ ). In addition to standard toxicity and survival parameters, we report unique outcomes as FFWD - Freedom from widespread dissemination, FFNT - Freedom from the need of subsequent treatment and functional survival with Karnofsky performance status higher than $70 \%$. A total of 110 patients were prospectively evaluated, $60 \%$ and $40 \%$ were treated for lung and liver oligometastatic disease, respectively. No grade 3 or 4 acute toxicities (CTCAE) were reported. With median follow up of 22.2 months and 2-year overall survival of $88.3 \%$, four patients $(6.1 \%)$ experienced local progression in the lung SBRT cohort. In the liver SBRT cohort, median follow up was 33 months, 2 -year overall survival was $68.5 \%$ and 11 patients (25\%) experienced local and $36(81.8 \%)$ distal progression. Higher $\mathrm{BED}_{10}$ of $150-170$ Gy compared to $100-150 \mathrm{~Gy}$ was an independent positive prognostic factor for local progression-free survival for all patients with hazard ratio 0.25 . This confirms SBRT ablative radiobiology effects to be independent of OD primary histology and location. The best outcomes in terms of FFNT were observed in the multivariable analysis of patients with 1-2 lung OD compared to both the liver OD cohort and patients with more than 2 lung metastases. Better FFNT in the liver SBRT cohort was observed in patients with 1-2 liver metastases and in patients whose liver OD was irradiated by higher $\mathrm{BED}_{10}$. In conclusion, SBRT is a suitable option for patients who are not surgical candidates; with approximately $30 \%$ of patients not requiring subsequent treatment 2 years after SBRT. We believe that this treatment represents a safe and effective option for oligometastatic involvement in patients with various primary tumors.
\end{abstract}

Key words: oligometastatic disease, stereotactic body radiotherapy, ablative radiotherapy, liver metastases, lung metastases

Localized metastasis-directed therapy of oligometastatic disease (OD) is the rapidly evolving standard of care in many cancer centers. Oligometastases are typically defined as 5 or fewer metastases in a limited number of organ systems and limited organ involvement $[1,2]$. Comparing surgical resection, radio-frequency and cryoablation, radiation therapy (RT) is the preferred option in select patients due to its non-invasive nature, especially in patients medically unfit for surgery or technically not surgical candidates. All these methods can result in improvement in the quality of life, render some patients free of disease for extended periods of time and enhance potential cure $[3,4]$.

When treating metastatic disease for palliative intent, individual RT approaches must be utilized for best patient results. Definitions of prescribed RT parameters and determination of the ideal target volume for RT is a trade-off between achieving tumor control and minimizing treatment-related toxicity. With currently available devices for patient immobilization, better imaging techniques and advanced treatment delivery systems, the principles of stereotactic body radiation 
therapy (SBRT; delivering high dose of RT in a small number of fractions) can be safely applied in the treatment of oligometastases. SBRT is a non-invasive short-term ambulatory treatment which meets the criteria for high-quality palliative care of patients with metastatic disease. Moreover, there is minimal delay in the onset of subsequent chemotherapy compared to the more common fractionated RT schedules because treatment is completed in 1-5 days. SBRT can also delay progression and postpone the need for additional systemic therapy for some treatment-resistant tumors.

Many institutions have published treatment outcomes of patients treated with high-dose RT for limited metastases to the lung, liver, adrenal gland and metastatic lymphatic spread [5-11], including reports of possibly more toxic singlefraction SBRT [12]. Nevertheless, there is a paucity of data comparing different general practical approaches in daily clinical SBRT for oligometastases as is the target definitions or dose normalization for example. With rapidly evolving RT systems and relatively rare indications, such comparative trials will most likely never be conducted.

Further examples of SBRT outcomes are therefore required to strengthen the level of evidence for future standards of care. Existing trials of SBRT for oligometastases report 2-year local control rates of approximately $80 \%, 2-3$ year diseasefree survival rates of approximately $20 \%$ and $2-3$ years overall survival rates of $25-40 \%$; and this is comparable to surgical series $[3,13,14]$.

Evaluating effectiveness of SBRT according to anatomical metastases location is important for studying special techniques for treatment and immobilization of oligometastases. However, these heterogeneous patient groups prove difficult for evaluation of SBRT effectiveness in various primary tumors. When oligometastatic patients are classified according to the histopathology of their disease (analogy can be made to the so called basket trials in medical oncology), the results of the local treatment can be clinically much more usable. The results of SBRT of oligometastases from non-small cell lung cancer, colorectal cancer, breast, kidney, melanoma and sarcoma are now available [15-19]. There remains the need for additional studies comparing SBRT effects on oligometastases in various primary tumors.

The aim of the current prospective single institutional study is to analyze in unselected cohort of liver and lung OD patients from real-world clinical practice the long-term survival, tumor control outcomes and safety of SBRT (radical ablative RT with biological equivalent dose $\mathrm{BED}_{10}>100 \mathrm{~Gy}$ ) for oligometastases according to histopathology of their primary cancers or according to timing of development of OD [20].

\section{Patients and methods}

Patients. Patients with cancer history and 1-3 radiographically obvious metastatic lesions were referred for SBRT in the Masaryk Memorial Cancer Institute, Brno,
Czech Republic between October 2010 and September 2017. These were then screened for eligibility in this single-institutional prospective study. The eligibility criteria included age $\geq 18$ years and Karnofsky performance status $\geq 70 \%$. Furthermore, the diagnostic ${ }^{18} \mathrm{~F}$-fluorodeoxyglucose $\left({ }^{18} \mathrm{~F}-\mathrm{FDG}\right)$ PET (or PET/CT) was performed before the inclusion of each patient. Newly proven polymetastatic disease of more than 5 metastases led to exclusion, and those patients underwent systemic treatment. Several patients who developed additional metastatic disease after the first course of SBRT had additional SBRT courses, and their status prior to these additional SBRT formed the baseline.

SBRT technique. Lung and liver SBRT was achieved with precise four-dimensional CT (4DCT)-based planning and ensuring reliable and reproducible immobilization of all patients. This included the management of respiratory movements by navigation during each RT fraction using a linear accelerator equipped with integrated imaging systems and by ensuring physical safety quality assurance prior to irradiation [21]. The Elekta stereotactic body frame was used for patient fixation to minimize rotational shift and patient movement on the irradiation table [22]. New frameless fixation products by Orfit Industries and CIVCO Medical Solutions combined with 6D Perfect Pitch Varian Table has been used since January 2016, and epigastrium compression was utilized for minimization of breathing movements of the diaphragm and liver[23].

The 4DCT (2-3 mm thick slices) scanning was employed for tumor movement management during planning CT study acquisition. The data from MR and PET/CT examinations were used to increase accurate identification and delineation of the target volumes. The internal target volume (ITV) concept was used for target volume definition. Gross tumor volume (GTV) was drawn as a tumor visible on CT or CT/ MRI fusion without any margins and contoured separately as inspiration GTV, middle expiration GTV, deepest expiration GTV and middle inspiration GTV during the normal breathing cycle. Subsequently, ITV was created encompassing all these GTVs. No expansion from ITV to the clinical target volume (CTV) was used, and planning target volume (PTV) was delineated with 3 to 5 -mm extent in all directions from ITV to accommodate set-up and internal margin errors in the lung and liver targets, respectively. The prescribed radiation dose was planned and optimized to this final PTV [24].

Risk adaptive concept was used for dose prescription and calculation - the dose per fraction and total dose were determined using the dose volume histogram of the organs at risk [25]. Ablative dose of radiation was prescribed at $\mathrm{BED}_{10}>100 \mathrm{~Gy}$, with preferred dose schedule of $5 \times 11 \mathrm{~Gy}$ ( $55 \mathrm{~Gy})$ and $3 \times 18 \mathrm{~Gy}(54 \mathrm{~Gy})$ fractions. Dose per fraction was reduced when dose constraints were not met.

Treatment plans were created by the Eclipse planning system (Varian, v.11.2) with AAA algorithm, and delivered by linear accelerator equipped with Rapid Arc technology [26]. The pre-treatment correction of patient position was 
performed directly on the irradiation table by the cone-beam computed tomography (CBCT) on-board imagine system which is an integral part of the linear accelerator [27]. To ensure patient safety, each plan was verified using gamma analysis as a part of standard quality assurance process. Adequate target coverage was achieved when $98-100 \%$ of the PTV was covered by $95-100 \%$ of the prescribed dose, as clinically appropriate. Dose gradient was also evaluated so that treatment plans met the number of organs at risk dosevolume constraints [28]. The treatment was delivered by linear accelerator Varian Clinac iX, and by Varian TrueBeam STX v. 2.5 after 2016.

Patient follow-up, response and toxicity assessment. Patients were followed-up during and at the end of irradiation according to established institutional standards of care. They were examined every 3 months in the first year after SBRT, every 4 months in the second year, in subsequent years every 6 months and once a year after 5 years. PET/CT evaluated treatment response as the difference in metastasis size and tumor cell viability. Local recurrence was defined as a new tumor lesion in the irradiated region or as the increase in tumor size for more than $20 \%$ with corresponding avidity on PET scan. National Cancer Institute's Common Toxicity Criteria for Adverse Events scale (CTCAE) then evaluated the side effects. Those which occurred within 90 days of SBRT were defined as acute toxicity; and as chronic toxicity after this period. All toxicity records were based on physician report or laboratory data.

Statistical analysis and endpoints. Frequency tables and descriptive statistics were employed for basic characteristics. Several endpoints were defined in time-to-event analyses. Wide-spread distant metastasizing is defined as distant progression not amenable to resection or local ablation therapy; via SBRT, radio-frequency ablation or embolization. The freedom from widespread distant metastasis (FFWD) [29], overall survival rates (OS), freedom from new treatment (FFNT), functional survival (survival until the drop below Karnofsky performance status of 70\%) and local and distant control were all estimated by Kaplan-Meier actuarial survival analysis and log-rank test. OS was calculated from the date of completed SBRT until death or the last follow-up visit, and FFWD was defined from the date of finished SBRT until death, widespread distant progression or the last radiographic study.

Local failure was scored as an event in local progression free survival analysis when any treated lesion increased by $20 \%$ (the Response Evaluation Criteria In Solid Tumors criteria version 1.1), or when local failure was confirmed pathologically. The time to progression was defined as the time from the end of SBRT until the date of a new local/regional lesion in the lung/liver but outside the irradiated region or distant extra pulmonary/hepatic progression. SBRT outcomes were also evaluated with patients grouped according to different OD types: (1) first OD at patient's history of present illness, (2) former locally treated OD and current new onset of OD,
(3) former poly-metastatic disease controlled by chemotherapy and current new onset of OD and 4) current polymetastatic disease already treated by chemotherapy and by SBRT to some lesions. Multivariable analysis was performed using the Cox proportional hazard model based on results of univariable analysis. All significance testing was performed at the 0.05 level by $\mathrm{R}$ software version 3.2.4.

\section{Results}

Patients' characteristics. A total of 110 patients met inclusion criteria between October 2010 and September 2017 and these were further analysed. The median age was 65.2 years and $47 \%$ were men. Patient characteristics are summarized in Table 1, including the timing of OD, type of OD and relationship of SBRT to systemic treatment. The majority of liver SBRT patients were patients with colorectal cancer (59 patients, 53.6\%).

Acute grade 1 and 2 toxicity occurred in 24 patients (21.8\%); 13 cases (19.7\%) in lung SBRT cohort and 11 cases (25.0\%) in liver SBRT cohort - mainly nausea in 8 cases (7.3\%), fatigue and weakness in 9 cases (8.2\%), dry cough in 5 cases (4.5\%) and inter-costal nerve irritation in 2 cases $(1.8 \%)$. No grade 3 or 4 acute side effects were reported. Late toxicity occurred in 17 patients (15.5\%); 11 patients (10.0\%) suffered from symptomatic pneumonitis, with 6 patients treated with antibiotics and 5 with antibiotics and corticosteroids with maximum duration of steroids for two months; 2 patients (1.8\%) suffered from inter-costal nerve irritation and 4 patients (3.6\%) from asymptomatic rib fracture. No radiation induced liver disease was observed.

SBRT treatment characteristics. All patients were treated with radical ablative dose $\left(\mathrm{BED}_{10}>100 \mathrm{~Gy}\right)$ with the most common prescription of $5 \times 11 \mathrm{~Gy}\left(\mathrm{BED}_{10}=150\right)$ in both lung and liver SBRT cohorts. The overall median PVT volume was $28.4 \mathrm{ccm}$, and detailed SBRT parameters are summarized in Table 2.

Local control and time to event data. With median follow up of 22.2 months and 2-year overall survival of $88.3 \%$, four patients $(6.1 \%)$ experienced local progression in the lung SBRT cohort and 35 patients (53.0\%) experienced distal progression (median time to distal progression 14.2 months after the end of SBRT). Median FFWD survival was 38.9 months with 17 patients $(25.8 \%)$ having widespread dissemination. Thirty-six patients $(54.5 \%)$ needed subsequent treatment (median FFNT survival 15.4 months). Eleven patients (16.7\%) experienced worse functional status with $70 \%$ decrease in Karnofsky performance status (median functional survival not reached).

Corresponding results in the liver SBRT cohort are as follow: median follow up of 33.0 months, 2-year overall survival $68.5 \%$. Eleven patients $(25.0 \%)$ had local and 36 $(81.8 \%)$ distant progression (median time to local progression was not reached and median time to distal progression was 6.2 months). Median FFWD survival was 11.6 months 
(28 patients (63.6\%) had widespread dissemination). 36 patients $(81.8 \%)$ needed subsequent treatment (median FFNT survival 9.4 months). Median functional survival was 35.5 months (17 patients, 38.6\%, had an event). The remaining survival parameters are displayed in Figure 1 and summarized in Table 3.

Univariable analysis of all patients revealed that local control was significantly influenced by OD liver location (HR $4.66)$, colorectal cancer $(\mathrm{HR}>10)$, by histology (adenocarcinoma-gastrointestinal worse than the others, HR 14.1) and timing of $\mathrm{OD}$ (OD at the time of initial diagnosis is worse than others, HR 0.20). However, local control was better with higher $\mathrm{BED}_{10}\left(\mathrm{BED}_{10} 150-170\right.$ vs. 100-150, HR 0.29, $\left.\mathrm{p}=0.088\right)$.
Neither the number of irradiated metastases nor the relationship of SBRT to systemic treatment or SBRT characteristics (PTV volume) influenced local control $(\mathrm{p}=0.18)$. The corresponding values for lung and liver SBRT cohorts are summarized in Figure 2 and Supplementary Table 1.

Regardless of primary diagnosis, multivariable analysis determined that local control was independently influenced by adenocarcinoma-gastrointestinal histology (HR $10.6, p=0.025$ ), gender (men were worse; HR 3.9, $\mathrm{p}=0.037$ ), timing of OD not present at the time of initial diagnosis (HR $0.27, \mathrm{p}=0.023)$ and higher $\mathrm{BED}_{10}(150-170 \mathrm{~Gy}$ compared to $100-150 \mathrm{~Gy}$; HR $0.25, \mathrm{p}=0.07)$. The overall survival was independently influenced by adenocarcinoma gastrointes-

Table 1. Basic patients' characteristics.

\begin{tabular}{|c|c|c|c|}
\hline Patients characteristic & $\begin{array}{c}\text { All patients } \\
\mathrm{n}=110(100 \%)\end{array}$ & $\begin{array}{l}\text { Lung SBRT } \\
\mathrm{n}=66(60 \%)\end{array}$ & $\begin{array}{l}\text { Liver SBRT } \\
\mathrm{n}=\mathbf{4 4}(\mathbf{4 0 \% )}\end{array}$ \\
\hline \multicolumn{4}{|l|}{ Age (years) } \\
\hline Median, range & $65.2 ; 34.4-83$ & $67.5 ; 35.3-82.9$ & $59.5 ; 34.4-77.2$ \\
\hline \multicolumn{4}{|l|}{ Sex } \\
\hline Men (\%) & $52(47.3 \%)$ & $30(45.5 \%)$ & $22(50.0 \%)$ \\
\hline \multicolumn{4}{|l|}{ Primary diagnosis } \\
\hline Colorectal cancer & $59(53.6 \%)$ & $27(40.9 \%)$ & $32(72.7 \%)$ \\
\hline Breast cancer & $18(16.4 \%)$ & $11(16.7 \%)$ & $7(15.9 \%)$ \\
\hline Lung cancer & $14(12.7 \%)$ & $14(21.2 \%)$ & $0(0.0 \%)$ \\
\hline Renal cancer & $9(8.2 \%)$ & $9(13.6 \%)$ & $0(0.0 \%)$ \\
\hline Other & $10(9.1 \%)$ & $5(7.6 \%)$ & $5(11.4 \%)$ \\
\hline \multicolumn{4}{|l|}{ Histology } \\
\hline Adenocarcinoma gastrointestinal & $65(59.1 \%)$ & $35(53.0 \%)$ & $30(68.2 \%)$ \\
\hline Ductal breast carcinoma & $16(14.5 \%)$ & $9(13.6 \%)$ & $7(15.9 \%)$ \\
\hline Squamous cell carcinoma & $9(8.2 \%)$ & $9(13.6 \%)$ & $0(0.0 \%)$ \\
\hline Renal cell carcinoma & $9(8.2 \%)$ & $5(7.6 \%)$ & $4(9.1 \%)$ \\
\hline Other & $11(10.0 \%)$ & $8(12.2 \%)$ & $3(6.8 \%)$ \\
\hline \multicolumn{4}{|l|}{ Number of metastases } \\
\hline 1 & $73(66.4 \%)$ & $43(65.2 \%)$ & $30(68.2 \%)$ \\
\hline 2 & $29(26.4 \%)$ & $18(27.3 \%)$ & $11(25.0 \%)$ \\
\hline 3 & $8(7.2 \%)$ & $5(7.5 \%)$ & $3(6.8 \%)$ \\
\hline \multicolumn{4}{|l|}{ Timing of OD } \\
\hline At the time of initial diagnosis & $23(20.9 \%)$ & $8(12.1 \%)$ & $15(34.1 \%)$ \\
\hline During primary treatment & $7(6.4 \%)$ & $4(6.1 \%)$ & $3(6.8 \%)$ \\
\hline Until 12 month after the primary treatment & $23(20.9 \%)$ & $13(19.7 \%)$ & $10(22.7 \%)$ \\
\hline \multicolumn{4}{|l|}{ More than 12 month after primary treatment } \\
\hline & $57(51.8 \%)$ & $41(62.1 \%)$ & $16(36.4 \%)$ \\
\hline \multicolumn{4}{|l|}{ Type of OD } \\
\hline First OD at patient's HPI & $41(37.2 \%)$ & $24(36.4 \%)$ & $17(38.6 \%)$ \\
\hline Former locally treated OD and current new onset of OD & $43(39.1 \%)$ & $31(47.0 \%)$ & $12(27.3 \%)$ \\
\hline $\begin{array}{l}\text { Former polymetastatic disease controlled by chemotherapy } \\
\text { and current new onset of OD }\end{array}$ & $18(16.4 \%)$ & $8(12.1 \%)$ & $10(22.7 \%)$ \\
\hline $\begin{array}{l}\text { Current polymetastatic disease treated by chemotherapy ar } \\
\text { by SBRT to some of the lesions }\end{array}$ & $8(7.3 \%)$ & $3(4.5 \%)$ & $5(11.4 \%)$ \\
\hline \multicolumn{4}{|l|}{ Relation of SBRT to systemic treatment } \\
\hline No systemic therapy & $64(58.2 \%)$ & $43(65.1 \%)$ & $21(47.7 \%)$ \\
\hline Regression of MTS on previous systemic therapy & $23(20.9 \%)$ & $12(18.2 \%)$ & $11(25.0 \%)$ \\
\hline Progression of MTS on previous systemic therapy & $23(20.9 \%)$ & $11(16.7 \%)$ & $12(27.3 \%)$ \\
\hline
\end{tabular}

Abbreviations: OD, oligometastatic disease; HPI, history of patient illness; MTS, metastasis 
Table 2. SBRT treatment prescription characteristics.

\begin{tabular}{|c|c|c|c|}
\hline SBRT characteristic & $\begin{array}{l}\text { All patients } \\
(\mathrm{n}=110)\end{array}$ & $\begin{array}{l}\text { Lung SBRT } \\
(\mathrm{n}=66)\end{array}$ & $\begin{array}{c}\text { Liver SBRT } \\
(\mathrm{n}=44)\end{array}$ \\
\hline \multicolumn{4}{|l|}{ PTV volume } \\
\hline median (min-max) & $28.4(4.3-143.2)$ & $21.2(4.3-125.1)$ & $49.3(12-134.2)$ \\
\hline \multicolumn{4}{|l|}{ Dmin_ITV } \\
\hline median (min-max) & $53.0(34.1-67.6)$ & $53.1(34.1-64.1)$ & $53(42.9-67.6)$ \\
\hline \multicolumn{4}{|l|}{ Dmin_PTV } \\
\hline median (min-max) & $45.5(20.2-52.4)$ & $44.3(20.2-52.4)$ & $46.7(34.8-52.2)$ \\
\hline \multicolumn{4}{|l|}{ Dmax } \\
\hline median (min-max) & $60(50.2-81.7)$ & $61.3(52-81.7)$ & $59.6(50.2-79.4)$ \\
\hline \multicolumn{4}{|l|}{$\mathrm{BED}_{10}$} \\
\hline $\operatorname{median}(\min -\max )$ & $115(100-170)$ & $115(100-170)$ & $115(100-150)$ \\
\hline 170 (3×20 Gy) & $2(1.8 \%)$ & $2(3.0 \%)$ & $0(0 \%)$ \\
\hline 150 (3×18 Gy) & $34(30.9 \%)$ & $22(33.3 \%)$ & $12(27.3 \%)$ \\
\hline 125 (3×16 Gy) & $1(0.9 \%)$ & $1(1.5 \%)$ & $0(0 \%)$ \\
\hline 115 (5×11 Gy) & $57(51.8 \%)$ & $29(43.9 \%)$ & $28(63.6 \%)$ \\
\hline 105 (8×7.5 Gy) & $3(2.7 \%)$ & $3(4.6 \%)$ & $0(0 \%)$ \\
\hline 100 (5×10 Gy) & $13(11.9 \%)$ & $9(13.7 \%)$ & $4(9.1 \%)$ \\
\hline
\end{tabular}

Abbreviations: SBRT: stereotactic body radiation therapy, PTV: planning target volume, ITV: internal target volume, min: minimum, max: maximum,

Dmin_ITV: minimal dose in ITV, Dmin_PTV: minimal dose in PTV, Dmax: maximal dose, BED10: biological effective dose when $\alpha / \beta$ equals 10 , Gy: Gray.

Table 3. Time to event analyses.

\begin{tabular}{|c|c|c|c|c|}
\hline Time to event analysis & $\begin{array}{c}\text { All patients } \\
(\mathrm{n}=110)\end{array}$ & $\begin{array}{c}\text { Lung SBRT } \\
(\mathrm{n}=66)\end{array}$ & $\begin{array}{c}\text { Liver SBRT } \\
(\mathrm{n}=44)\end{array}$ & $\begin{array}{c}\mathrm{p} \text {-value } \\
\text { (liver vs. lung) }\end{array}$ \\
\hline Median follow up & 29.0 & 22.2 & 33.0 & - \\
\hline Overall survival & & & & 0.02 \\
\hline number of events & $26(26.3 \%)$ & $8(14.3 \%)$ & $18(40.9 \%)$ & \\
\hline 2 -year & $78.1 \%$ & $88.3 \%$ & $68.5 \%$ & \\
\hline 3-year & $64.9 \%$ & $80.2 \%$ & $51.8 \%$ & \\
\hline Local PFS & & & & $<0.01$ \\
\hline number of events & 15 & 4 & 11 & \\
\hline 2-year & $82.5 \%$ & $92.2 \%$ & $68.2 \%$ & \\
\hline 3-year & $75.8 \%$ & $85.6 \%$ & $61.4 \%$ & \\
\hline Distal PFS & & & & $<0.01$ \\
\hline number of events & 71 & 35 & 36 & \\
\hline 2-year & $29.7 \%$ & $39.8 \%$ & $16.6 \%$ & \\
\hline 3-year & $21.4 \%$ & $29.0 \%$ & $11.1 \%$ & \\
\hline Widespread dissemination & & & & $<0.01$ \\
\hline number of events & 45 & 17 & 28 & \\
\hline 2-year FFWD & $57.2 \%$ & $73.9 \%$ & $38.1 \%$ & \\
\hline 3-year FFWD & $40.0 \%$ & $56.0 \%$ & $21.4 \%$ & \\
\hline Need of new treatment & & & & $<0.01$ \\
\hline number of events & 72 & 36 & 36 & \\
\hline 2-year FFNT & $27.0 \%$ & $38.6 \%$ & $12.2 \%$ & \\
\hline 3-year FFNT & $20.2 \%$ & $29.2 \%$ & $9.1 \%$ & \\
\hline Functional survival & & & & 0.15 \\
\hline number of events & 28 & 11 & 17 & \\
\hline 2-year functional survival & $75.9 \%$ & $84.0 \%$ & $67.6 \%$ & \\
\hline 3-year functional survival & $56.9 \%$ & $64.6 \%$ & $49.2 \%$ & \\
\hline
\end{tabular}

Abbreviations: SBRT: stereotactic body radiation therapy, PFS: progression-free survival, FFWD: freedom from widespread distant metastasis, FFNT: freedom from a new treatment, functional survival: drop below Karnofsky performance status of $70 \%$ ). 

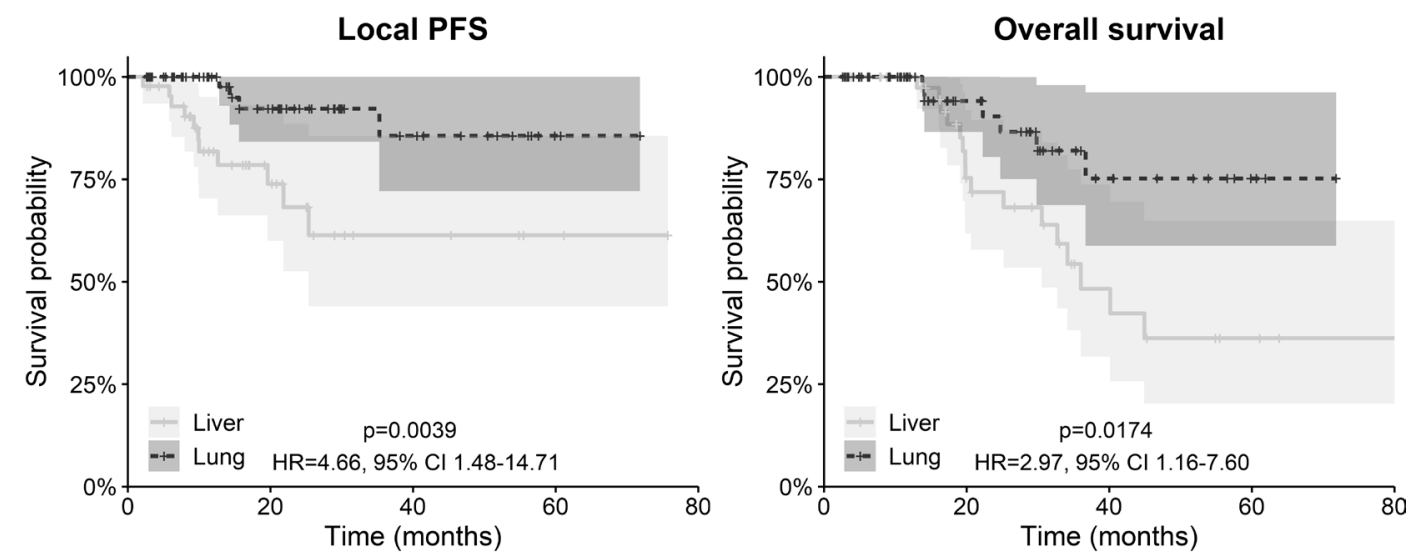

Distal PFS
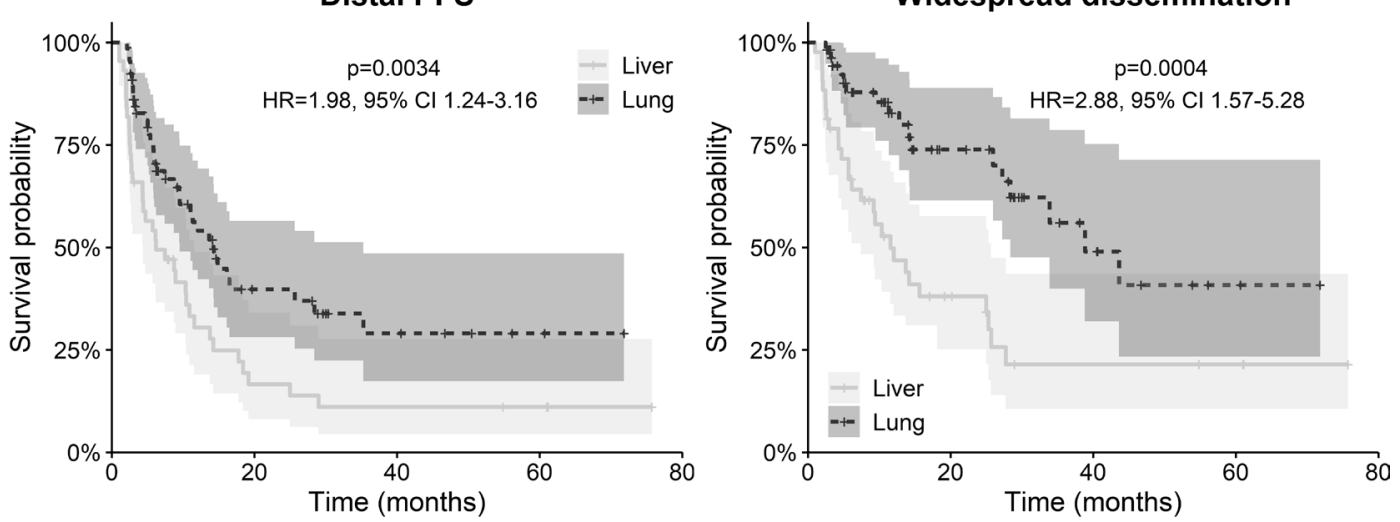

Need of new treatment
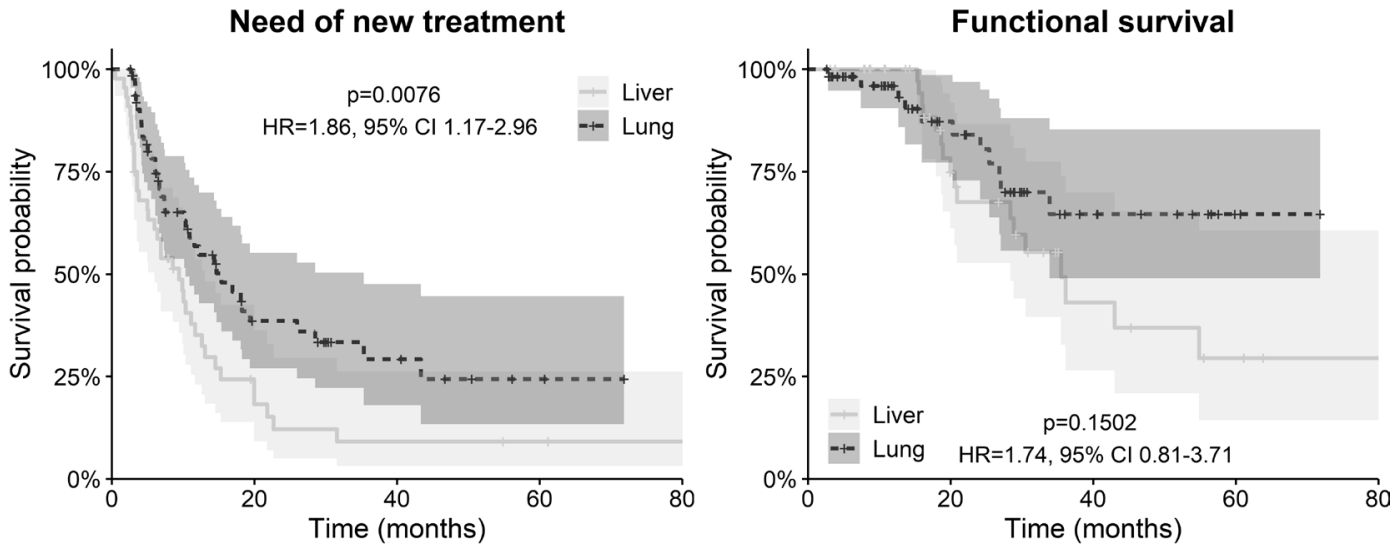

Figure 1. Kaplan-Meier survival estimation of local PFS (progression free survival), overall survival, distant PFS, time to widespread dissemination, time to requiring new therapy and time of functional survival in liver and lung cohorts.

tinal histology (HR 2.5, p=0.045), gender (men better; HR $0.3, \mathrm{p}=0.015$ ) and by the PTV volume (higher values worse; HR 1.02, $\mathrm{p}=0.001)$. Table 4 lists further significant variables in multivariable analysis, including separate analysis of each SBRT cohort. Finally, Figure 3 highlights colorectal cancer results because this provides the greater percentage of patients in our cohort (59 patients, 53.6\%). The median local PFS was not reached, with median overall survival at 45 months.

\section{Discussion}

The treatment outcomes of patients irradiated by SBRT for their oligometastatic lung and liver disease were evaluated in this large single institutional study focused on patients treated in routine clinical practice. Real-world evidence research is currently an increasingly important supplement to basic and clinical research, especially in radiotherapy where there are many different approaches to specific treatment delivery. We 


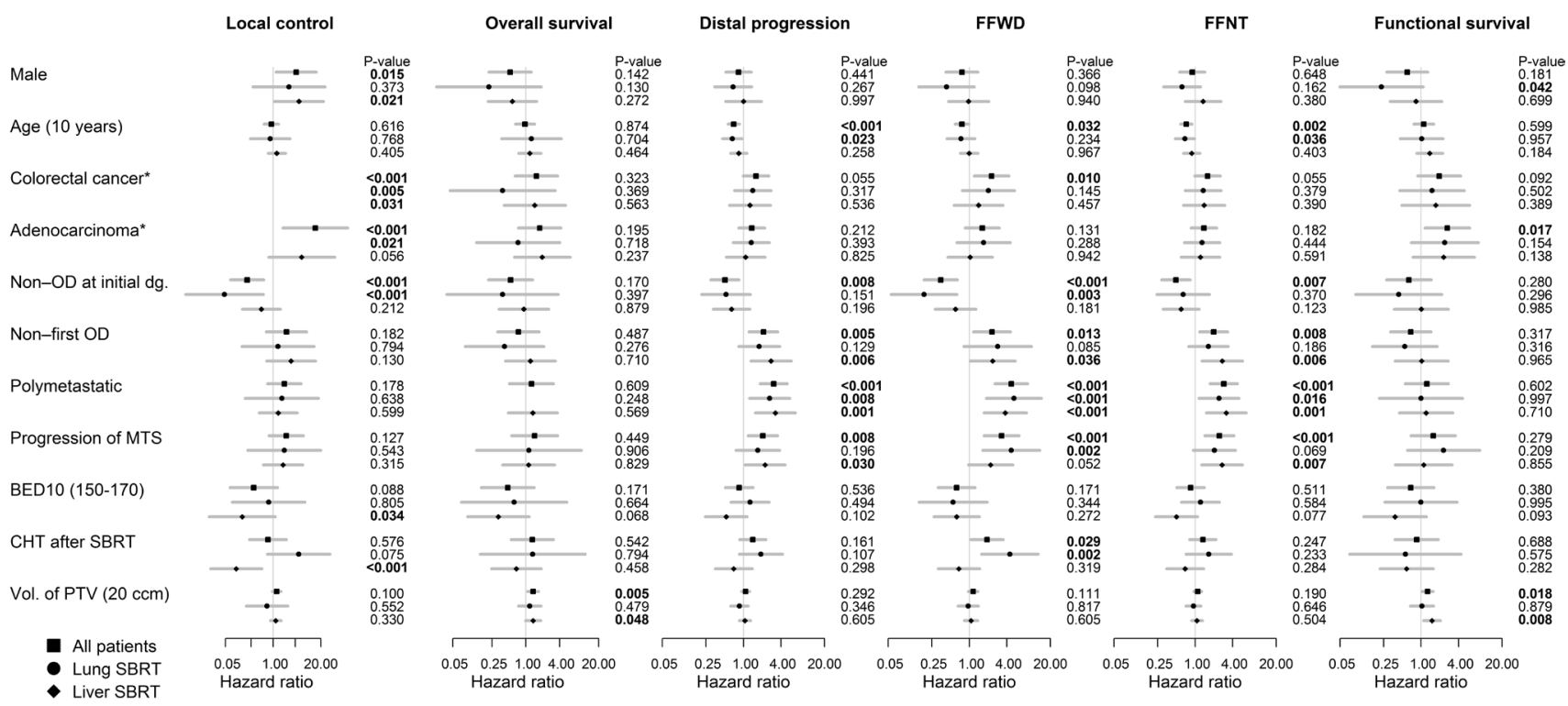

Figure 2. Results of univariable analysis of six predefined times to event analyses. ${ }^{*}$ Hazard ratios are not shown because there are no events in one group. Abbreviations: OD: oligometastases, MTS: metastasis, BED10: biological effective dose when $\alpha / \beta$ equals 10, CHT: chemotherapy, SBRT: stereotactic body radiation therapy, PTV: planning target volume, FFWD: freedom from widespread distant metastasis, FFNT: freedom from new treatment.

prospectively collected data on toxicity and local and distant control. SBRT itself was performed without any clinical trial specific protocol, what reflects routine clinical practice. Univariable analysis determined that worse local control and overall survival occurred in SBRT liver patients than in the lung SBRT cohort (HR 4.66, $\mathrm{p}=0.004$ and HR 2.97, $\mathrm{p}=0.017$ ). This may be explained by the higher proportion of colorectal cancer in the liver SBRT cohort, what can be proved by disappearance of significant difference in multivariable analysis. However, higher $\mathrm{BED}_{10}$ of $150-170 \mathrm{~Gy}$ compared to $100-150 \mathrm{~Gy}$ was an independent positive prognostic factor for local progression-free survival with HR 0.25 ; regardless of the location of the SBRT target. This confirmed SBRT radiobiological ablative effects independent of primary histology and OD location.

In addition to classical outcomes such as overall survival and local and distant control, we also focused on outcomes important for the patient's perception of the disease course - functional survival with Karnofsky performance status at least $70 \%$ (borderline where patients are able to care for themselves) and also the freedom from widespread distant metastasis (FFWD), mirrored by freedom from new treatment (FFNT) when the patient had adequate performance status for palliative treatment of widespread disease [29]. Since oligometastatic disease is treated by radical SBRT with curative potential [30-32], FFNT may be the most important outcome from patient view-point. To the best of our knowledge, this is the first report of FFNT of a large cohort of patients treated with high $\mathrm{BED}_{10}$ ablative dose. The ideal patient with significantly better FFNT based on multivariable analysis is one with lung OD or a patient without previous poly-metastatic disease treatment at the time of SBRT indication. While independently better FFNT was a most important index in liver patients with higher $\mathrm{BED}_{10}$ dose, younger age was more important in the lung cohort. In addition, all effort should be made to deliver $\mathrm{BED}_{10}$ dose $>150$ Gy in patients who benefit from SBRT of their oligometastases, provided risk factors are considered. BED is useful in comparing RT dosage because it accounts for fractionation effects in the observed results, provided that the different behaviour of early and late reacting tissues is considered. Interestingly, higher $\mathrm{BED}_{10}$ was also an independent factor for distant liver recurrence in the liver SBRT cohort with almost twice better distant liver PFS associated with higher SBRT dose. This may be speculatively explained based on the assumption that metastases ablation reduces sources for further metastasis, and also that subsequent liver metastases are related to previous liver OD rather than the original tumor. No studies have focused on this topic, but spatial correlations of liver failure after previous local treatment of liver oligometastases may address this issue $[33,34]$.

Surgery has been shown to be able to cure a proportion of oligometastatic patients. Surgery limitations (technical issues, advanced age, associated comorbidity or refusal by patient) have led to progressive implementation of SBRT as an alternative local ablative treatment option. SBRT is proven safe and effective and it achieves approximately $80 \%$ local control, with varying impact on survival dependent on associated prognostic factors [3].Despite promising results, SBRT has significant clinical challenges including 
Table 4. List of significant $(\mathrm{p}<0.05)$ prognostic factors in multivariable analyses expressed by HR and p-value.

\begin{tabular}{|c|c|c|c|}
\hline Multivariable analysis & $\begin{array}{l}\text { All patients } \\
(n=110)\end{array}$ & $\begin{array}{c}\text { Lung SBRT } \\
\qquad(n=66)\end{array}$ & $\begin{array}{c}\text { Liver SBRT } \\
\quad(n=44)\end{array}$ \\
\hline \multicolumn{4}{|l|}{ Local control } \\
\hline Adenocarcinoma-gastrointestinal & $10.6, \mathrm{p}=0.025$ & - & - \\
\hline $\operatorname{sex}(\operatorname{men})$ & $3.89, \mathrm{p}=0.037$ & - & \\
\hline non - OD at initial diagnosis & $0.27, \mathrm{p}=0.023$ & $0.04, \mathrm{p}=0.014$ & - \\
\hline progression of MTS on previous systemic therapy & - & - & $9.50, \mathrm{p}=0.007$ \\
\hline $\mathrm{BED}_{10}(150-170)$ & $0.25, \mathrm{p}=0.07$ & - & - \\
\hline systemic treatment after SBRT & - & - & $0.03, \mathrm{p}<0.001$ \\
\hline \multicolumn{4}{|l|}{ Overall survival } \\
\hline $\operatorname{sex}(\operatorname{men})$ & $0.3, \mathrm{p}=0.015$ & - & - \\
\hline non - first OD in patient's HPI & - & $0.42, \mathrm{p}=0.300$ & - \\
\hline adenocarcinoma_gastrointestinal & $2.5, \mathrm{p}=0.045$ & - & - \\
\hline PTV volume & $1.02, \mathrm{p}=0.001$ & - & $1.01, \mathrm{p}=0.053$ \\
\hline \multicolumn{4}{|l|}{ Distal progression } \\
\hline age (older) & $0.97, \mathrm{p}=0.004$ & $0.96, \mathrm{p}=0.050$ & - \\
\hline polymetastatic disease at patient's HPI & $2.76, \mathrm{p}<0.001$ & $2.34, \mathrm{p}=0.025$ & $3.26, \mathrm{p}=0.002$ \\
\hline $\mathrm{BED}_{10}(150-170)$ & - & - & $0.52, \mathrm{p}=0.099$ \\
\hline \multicolumn{4}{|l|}{ Freedom from widespread dissemination (FFWD) } \\
\hline liver location & $2.65, \mathrm{p}=0.002$ & - & - \\
\hline $\operatorname{sex}(\operatorname{men})$ & - & $0.28, \mathrm{p}=0.045$ & - \\
\hline adenocarcinoma_gastrointestinal & - & $4.75, \mathrm{p}=0.016$ & - \\
\hline $\mathrm{BED}_{10}(150-170)$ & - & $0.13, p=0.018$ & - \\
\hline progression of MTS on previous systemic therapy & - & $7.15, \mathrm{p}=0.003$ & - \\
\hline systemic treatment after SBRT & - & $5.5, \mathrm{p}=0.004$ & - \\
\hline polymetastatic disease at patient's HPI & $4.4, \mathrm{p}<0.001$ & - & $3.77, \mathrm{p}<0.001$ \\
\hline \multicolumn{4}{|l|}{ Freedom from the need of subsequent treatment (FFNT) } \\
\hline age (older) & - & $0.97, \mathrm{p}=0.074$ & - \\
\hline liver location & $1.76, \mathrm{p}=0.018$ & - & - \\
\hline $\mathrm{BED}_{10}(150-170)$ & - & - & $0.49, \mathrm{p}=0.073$ \\
\hline polymetastatic disease at patient's HPI & 2.77, $\mathrm{p}<0.001$ & $2.17, \mathrm{p}=0.043$ & $3.2, \mathrm{p}=0.002$ \\
\hline \multicolumn{4}{|l|}{ Functional survival } \\
\hline colorectal cancer & - & - & $22.56, p=0.005$ \\
\hline $\operatorname{sex}(\operatorname{men})$ & $0.35, \mathrm{p}=0.01$ & $0.08, \mathrm{p}=0.006$ & - \\
\hline adenocarcinoma_gastrointestinal & $3.71, \mathrm{p}=0.003$ & $3.81, \mathrm{p}=0.053$ & - \\
\hline non - first OD in patient's HPI & - & $0.23, \mathrm{p}=0.053$ & - \\
\hline non - OD at initial diagnosis & - & $0.15, \mathrm{p}=0.055$ & - \\
\hline volume of PTV & $1.01, \mathrm{p}=0.003$ & - & $1.02, \mathrm{p}=0.01$ \\
\hline
\end{tabular}

Abbreviations: SBRT: stereotactic body radiation therapy, HR: hazard ratio, OD: oligometastatic disease, BED10: biological effective dose when $\alpha / \beta$ equals 10, PTV: planning target volume, PTV: planning target volume, ITV: internal target volume, Dmin_ITV: minimal dose in ITV, Dmin_PTV: minimal dose in PTV, HPI: history of patient illness, MTS: metastasis.

identification of optimal patients for treatment with reasonable risk-benefit ratio. Our planned post-hoc analysis with longer follow-up and a greater number of patients in each subgroup is intended to provide clearer indication criteria. One example is future comparison of outcomes for patients with first OD presentation compared to that for OD second or further OD presence. In our current cohort, no significant difference in outcomes between these two groups were observed (Supplementary Figure 1). Nowadays, the selection of patients for SBRT is based on clinical criteria only. Despite the excellent local control achieved, the main progression pattern in these patients is systemic, and some patients progress to poly-metastatic disease less than 4 months after SBRT. Some clinical factors have been shown to be associated with poorer survival, including brain metastases, "adenocarcinoma_gastrointestinal" histology, and synchronous vs metachronous metastatic disease, some of them were also confirmed by our study. We also observed a significant corre- 
Local PFS

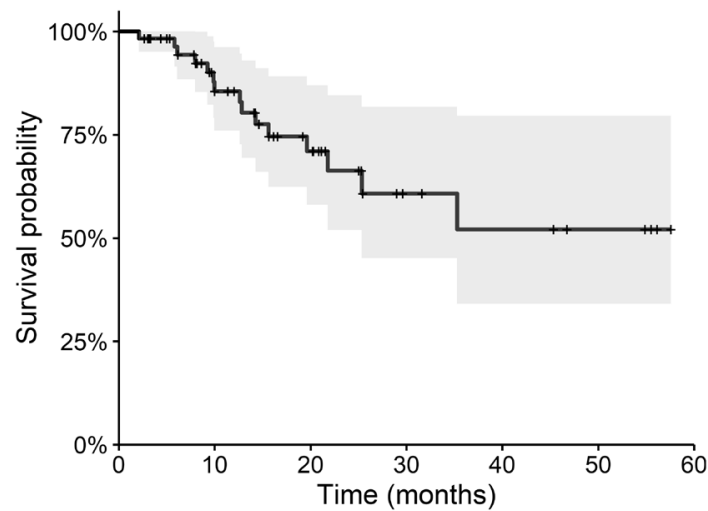

Distal PFS

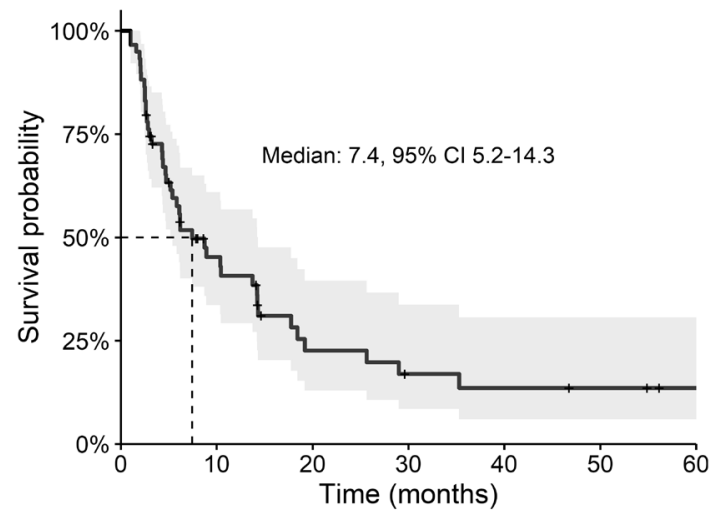

Need of new treatment

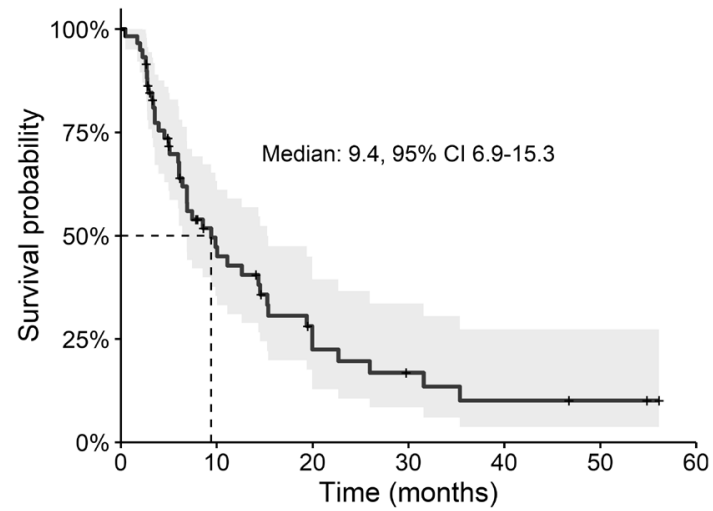

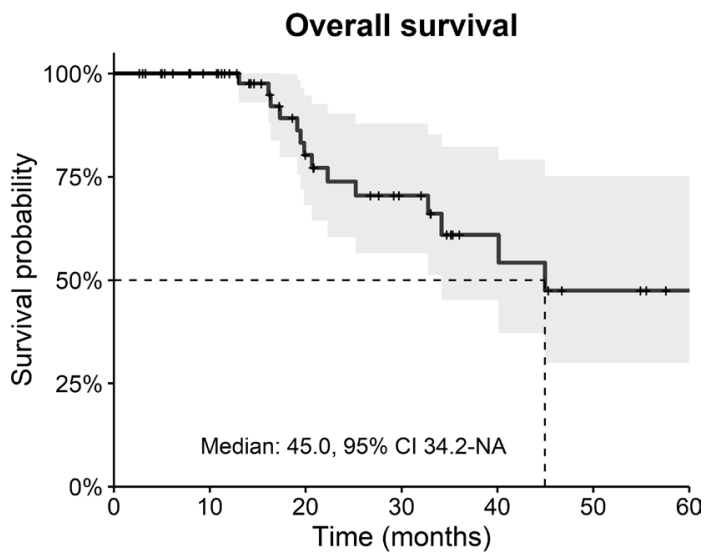

Widespread dissemination

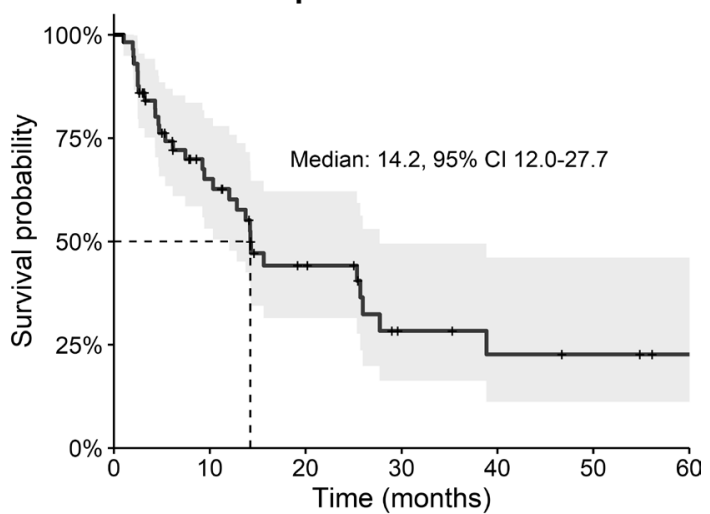

Functional survival

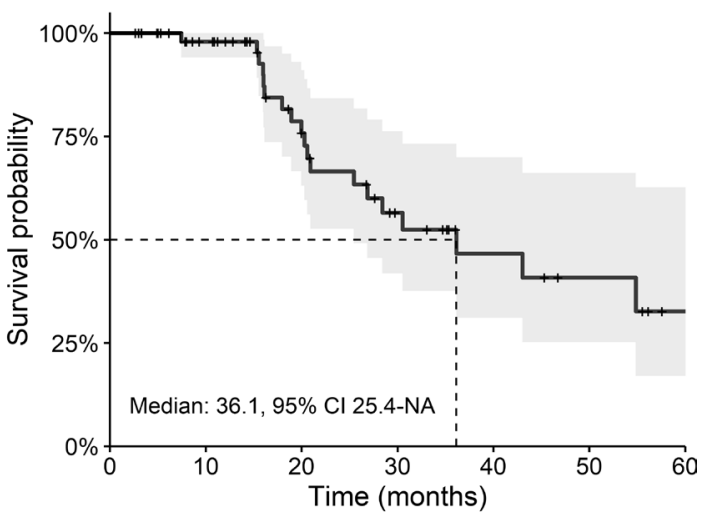

Figure 3. Kaplan-Meier survival estimation of local PFS (progression free survival), overall survival, distant PFS, time to widespread dissemination, time to requiring new therapy and time of functional survival in the colorectal cancer cohort ( $n=59$ patients).

lation with the PTV volume reflecting higher tumor burden as a risk factor for survival. Several limitations are acknowledged in our study. The aim to include all irradiated patients is both a strength and weakness of this analysis. Especially in the evaluation of potential effect of SBRT on overall survival, the results can be biased by inclusion of 8 polymetastatic patients who were irradiated to few metastases that did not responded to systemic treatment. The curative or palliative intent of SBRT must be defined in all patients prior to treatment. Considering localized oligometastatic disease and very high local dose used in our cohort $\left(\mathrm{BED}_{10}\right.$ higher than 100 Gy), it may be concluded that all patients in our study were treated with curative intent except of previously mentioned 8 patients. Even if this factor was not significant in multivariable analysis, these patients may not fulfil rigorous definitions of OD for curative local treatment $[1,2]$. A further limitation 
may be the combination of SBRT liver and lung patients. The location of metastasis was not an independent factor for local PFS in our study, and even if this is not important in evaluating local control after SBRT [25] other outcomes could be strongly influenced by the original histology or other details in the patient's history of presented disease which were not evaluated. This, for example, includes molecular subtypes of breast cancer [29].

In conclusion, herein we report the results of oligometastatic disease treated by radical SBRT ablation. This is a very effective and safe palliative treatment modality suitable for patients with oligometastatic liver or lung disease. SBRT is a suitable option for patients who cannot undergo surgery safely, because it is well tolerated and has minimal toxicity. SBRT is a standard curative treatment for oligometastatic involvement in various primary tumors, and almost $30 \%$ of our patients required no subsequent treatment 2 years afterwards. Finally, stereotactic body radiation therapy optimal doses, fractionation schemes, indications and detailed technical aspects currently require standardization.

Acknowledgements: This work was supported in part by the Ministry of Health, Czech Republic - Conceptual Development of Research Organization (MMCI 00209805), project MEYS-NPS I-LO1413 and Grant No. 19-00354. The results of this research were acquired in the CEITEC 2020 (LQ1601) project with the financial contribution made by the Ministry of Education, Youths and Sports of the Czech Republic within special support paid from the National Programme for Sustainability II funds.

\section{References}

[1] WEICHSELBAUM RR, HELLMAN S. Oligometastases revisited. Nat Rev Clin Oncol 2011; 8: 3783-382. https://doi. org/10.1038/nrclinonc.2011.44

[2] HELLMAN S, WEICHSELBAUM RR. Oligometastases. J Clin Oncol 1995; 13: 8-10. https://doi.org/10.1200/ JCO.1995.13.1.8

[3] TREE AC, KHOO VS, EELES RA, AHMED M, DEARNALEY DP et al. Stereotactic body radiotherapy for oligometastases. Lancet Oncol 2013; 14: e28-37. https://doi.org/10.1016/ S1470-2045(12)70510-7

[4] CORBIN KS, HELLMAN S, WEICHSELBAUM RR. Extracranial oligometastases: a subset of metastases curable with stereotactic radiotherapy. J Clin Oncol 2013; 31: 1384-1390. https://doi.org/10.1200/JCO.2012.45.9651

[5] NAVARRIA P, ASCOLESE AM, TOMATIS S, COZZI L, DE ROSE F et al. Stereotactic body radiotherapy (sbrt) in lung oligometastatic patients: role of local treatments. Radiat Oncol 2014; 9: 91. https://doi.org/10.1186/1748-717X-9-91

[6] SINGH D, CHEN Y, HARE MZ, USUKI KY, ZHANG H et al. Local control rates with five-fraction stereotactic body radiotherapy for oligometastatic cancer to the lung. J Thorac Dis 2014; 6: 369-374. https://doi.org/10.3978/j.issn.20721439.2013.12.03
[7] BASCHNAGEL AM, MANGONA VS, ROBERTSON JM, WELSH RJ, KESTIN LL et al. Lung metastases treated with image-guided stereotactic body radiation therapy. Clin Oncol (R Coll Radiol) 2013; 25: 236-241. https://doi. org/10.1016/j.clon.2012.12.005

[8] RICARDI U, FILIPPI AR, GUARNERI A, RAGONA R, MANTOVANI $C$ et al. Stereotactic body radiation therapy for lung metastases. Lung Cancer 2012; 75: 77-81. https:// doi.org/10.1016/j.lungcan.2011.04.021[9] CHANG DT, SWAMINATH A, KOZAK M, WEINTRAUB J, KOONG AC et al. Stereotactic body radiotherapy for colorectal liver metastases: a pooled analysis. Cancer 2011; 117: 4060-4069. https://doi.org/10.1002/cncr.25997

[10] RULE W, TIMMERMAN R, TONG L, ABDULRAHMAN R, MEYER J et al. Phase I dose-escalation study of stereotactic body radiotherapy in patients with hepatic metastases. Ann Surg Oncol 2011; 18: 1081-1087. https://doi.org/10.1245/ s10434-010-1405-5

[11] VAN DER POOL AEM, MENDEZ ROMERO A, WUNDERINK W, HEIJMEN BJ, LEVENDAG PC et al. Stereotactic body radiation therapy for colorectal liver metastases. $\mathrm{Br}$ J Surg 2010; 97: 377-382. https://doi.org/10.1002/bjs.6895

[12] GANDHIDASAN S, BALL D, KRON T, BRESSEL M, SHAW $\mathrm{M}$ et al. Single Fraction Stereotactic Ablative Body Radiotherapy for Oligometastasis: Outcomes from 132 Consecutive Patients. Clin Oncol (R Coll Radiol) 2018; 30: 178-184. https://doi.org/10.1016/j.clon.2017.11.010

[13] TOMLINSON JS, JARNAGIN WR, DEMATTEO RP, FONG Y, KORNPRAT P et al. Actual 10-year survival after resection of colorectal liver metastases defines cure. J Clin Oncol 2007; 25: 4575-4580. https://doi.org/10.1200/JCO.2007.11.0833

[14] PASTORINO U, BUYSE M, FRIEDEL G, GINSBERG RJ, GIRARD P et al. Long-term results of lung metastasectomy: prognostic analyses based on 5206 cases. J Thorac Cardiovasc Surg 1997; 113: 37-49. https://doi.org/10.1016/S00225223(97)70397-0

[15] COMITO T, COZZI L, CLERICI E, CAMPISI MC, LIARDO RL et al. Stereotactic Ablative Radiotherapy (SABR) in inoperable oligometastatic disease from colorectal cancer: a safe and effective approach. BMC Cancer 2014; 14: 619. https:// doi.org/10.1186/1471-2407-14-619

[16] JERECZEK-FOSSA BA, BOSSI-ZANETTI I, MAURO R, BELTRAMO G, FARISELLI L et al. CyberKnife robotic image-guided stereotactic radiotherapy for oligometastic cancer: A prospective evaluation of 95 patients/118 lesions. Strahlenther Onkol 2013; 189: 448-455. https://doi. org/10.1007/s00066-013-0345-y

[17] SOLE C V, LOPEZ GUERRA JL, MATUTE R, JAEN J, PUEBLA F et al. Stereotactic ablative radiotherapy delivered by image-guided helical tomotherapy for extracranial oligometastases. Clin Transl Oncol 2013; 15: 484-491. https://doi. org/10.1007/s12094-012-0956-2

[18] BAE SH, KIM M-S, CHO CK, KANG J-K, KANG HJ et al. High dose stereotactic body radiotherapy using three fractions for colorectal oligometastases. J Surg Oncol 2012; 106: 138-143. https://doi.org/10.1002/jso.23058 
[19] SALAMA JK, HASSELLE MD, CHMURA SJ, MALIK R, MEHTA $\mathrm{N}$ et al. Stereotactic body radiotherapy for multisite extracranial oligometastases: final report of a dose escalation trial in patients with 1 to 5 sites of metastatic disease. Cancer 2012; 118: 2962-2970. https://doi.org/10.1002/cncr.26611

[20] SETHI RA, BARANI IJ, LARSON DA, ROACH III M. (Eds.). Handbook of Evidence-Based Stereotactic Radiosurgery and Stereotactic Body Radiotherapy. Springer International Publishing, Cham 2016, p 245. ISBN 978-3-319-21897-7. https:// doi.org/10.1007/978-3-319-21897-7

[21] BURKON P, SLAMPA P, KAZDA T, SLAVIK M, PROCHAZKA T, VRZAL M. Stereotactic body radiation therapy for colorectal cancer liver metastases; early results. Klin Onkol 2012; 25 Suppl 2: 2S93-97.

[22] NAGATA Y, TAKAYAMA K, MATSUO Y, NORIHISA Y, MIZOWAKI T et al. Clinical outcomes of a phase I/II study of $48 \mathrm{~Gy}$ of stereotactic body radiotherapy in 4 fractions for primary lung cancer using a stereotactic body frame. Int J Radiat Oncol Biol Phys 2005; 63: 1427-1431. https://doi. org/10.1016/j.ijrobp.2005.05.034

[23] HEINZERLING JH, ANDERSON JF, PAPIEZ L, BOIKE T, CHIEN $S$ et al. Four-dimensional computed tomography scan analysis of tumor and organ motion at varying levels of abdominal compression during stereotactic treatment of lung and liver. Int J Radiat Oncol Biol Phys 2008; 70: 15711578. https://doi.org/10.1016/j.ijrobp.2007.12.023

[24] NAGATA Y, WULF J, LAX I, TIMMERMAN R, ZIMMERMANN $F$ et al. Stereotactic radiotherapy of primary lung cancer and other targets: results of consultant meeting of the International Atomic Energy Agency. Int J Radiat Oncol Biol Phys 2011; 79: 660-669. https://doi.org/10.1016/j. ijrobp.2010.10.004

[25] ONISHI H, SHIRATO H, NAGATA Y, HIRAOKA M, FUJINO $\mathrm{M}$ et al. Stereotactic body radiotherapy (SBRT) for operable stage I non-small-cell lung cancer: can SBRT be comparable to surgery? Int J Radiat Oncol Biol Phys 2011; 81: 1352-1358. https://doi.org/10.1016/j.ijrobp.2009.07.1751
[26] ONG CL, VERBAKEL WFAR, CUIJPERS JP, SLOTMAN BJ, LAGERWAARD FJ et al. Stereotactic radiotherapy for peripheral lung tumors: a comparison of volumetric modulated arc therapy with 3 other delivery techniques. Radiother Oncol 2010; 97: 437-442. https://doi.org/10.1016/j.radonc.2010.09.027

[27] PURDIE TG, BISSONNETTE J-P, FRANKS K, BEZJAK A, PAYNE D et al. Cone-beam computed tomography for on-line image guidance of lung stereotactic radiotherapy: localization, verification, and intrafraction tumor position. Int J Radiat Oncol Biol Phys 2007; 68: 243-252. https://doi. org/10.1016/j.ijrobp.2006.12.022

[28] BENEDICT SH, YENICE KM, FOLLOWILL D, GALVIN JM, HINSON W et al. Stereotactic body radiation therapy: the report of AAPM Task Group 101. Med Phys 2010; 37: 4078-4101. https://doi.org/10.1118/1.3438081

[29] MILANO MT, KATZ AW, ZHANG H, OKUNIEFF P. Oligometastases treated with stereotactic body radiotherapy: long-term follow-up of prospective study. Int J Radiat Oncol Biol Phys 2012; 83: 878-886. https://doi.org/10.1016/j. ijrobp.2011.08.036

[30] ALONGI F, ARCANGELI S, FILIPPI AR, RICARDI U, SCORSETTI M. Review and uses of stereotactic body radiation therapy for oligometastases. Oncologist 2012; 17: 11001107. https://doi.org/10.1634/theoncologist.2012-0092

[31] WILD AT, YAMADA Y. Treatment Options in Oligometastatic Disease: Stereotactic Body Radiation Therapy - Focus on Colorectal Cancer. Visc Med 2017; 33: 54-61. https://doi. org/10.1159/000454685

[32] AHMED KA, TORRES-ROCA JF. Stereotactic Body Radiotherapy in the Management of Oligometastatic Disease. Cancer Control 2016; 23: 21-29. https://doi. org/10.1177/107327481602300105

[33] NAVARRIA P, DE ROSE F, ASCOLESE AM. SBRT for lung oligometastases: Who is the perfect candidate? Reports Pract Oncol Radiother 2015; 20: 446-453. https://doi. org/10.1016/j.rpor.2014.11.005

[34] DE VIN T, ENGELS B, GEVAERT T, STORME G, DE RIDDER M. Stereotactic radiotherapy for oligometastatic cancer: a prognostic model for survival. Ann Oncol 2014; 25: 467-471. https://doi.org/10.1093/annonc/mdt537 